\title{
Mídia, Cultura do Consumo e Constituição da Subjetividade na Infância'
}

Resumo: Este texto tem como proposta oferecer as bases teóricas para a compreensão das implicações éticas da cultura do consumo e da mídia na constituição subjetiva da infância. Como estratégia metodológica, enfatizamos a articulação de diferentes autores, sobre questões que abarcam os temas relativos à subjetividade, ao consumo e à mídia com fragmentos de entrevistas realizadas com pais, professores, crianças

Cristiana Caldas Guimarães de Campos

Mestre em Psicologia Clínica pela PUC-Rio.

Membro do Grupo Interdisciplinar de Pesquisa da Subjetividade (GIPS).

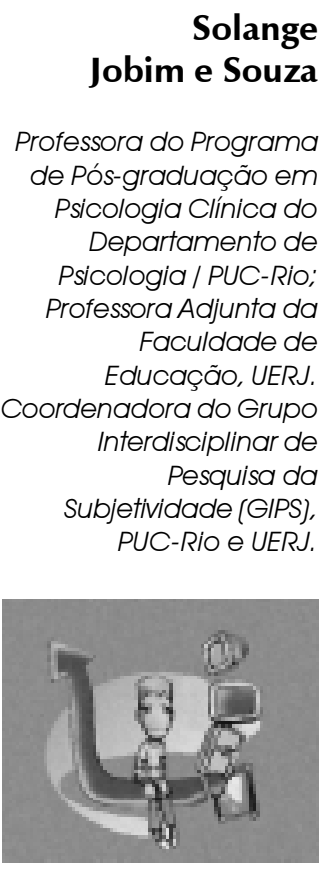
e adolescentes, abordando as transformações intersubjetivas na contemporaneidade. Na medida em que a construção do saber se dá na interlocução entre diferentes vozes que se posicionam no mundo e sobre o mundo, este texto pretende ser uma oportunidade de diálogo e conhecimento para elucidar os desafios da nossa época.

Palavras-Chave: Infância, mídia, ética, subjetividade.

Abstract: This text's proposal is to offer the theoretical basis to the understanding of the ethical implications of the consumer's culture and media in the subjective constitution of childhood. As a methodological strategy we emphasize the articulation of different authors, with questions which embrace themes related to subjectivity, consume and media, with fragments from interviews carried out with parents, teachers, children and adolescents, approaching the intersubjective transformations in contemporary times. As long as the construction of knowledge takes place in the conversation between different voices which reveal their view in the world as well as about the world, this text intends to be an opportunity of dialogue and knowledge to elucidate the challenges of our time.

Key Words: Infancy, mídia, ethics, subjectivity.

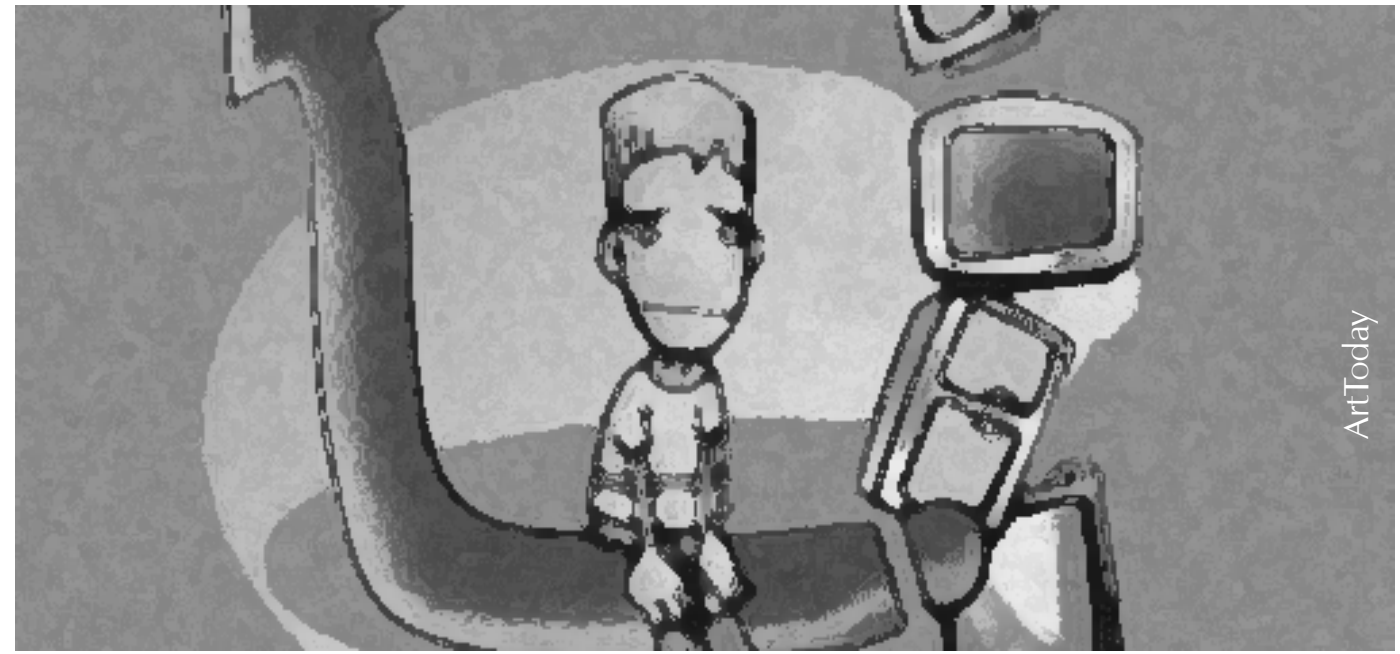

A contemporaneidade tem-se caracterizado pelas relações de produção e de consumo permeando as interações sociais. Temos acompanhado mudanças nas relações estabelecidas entre adultos e crianças, bem como o surgimento de uma nova produção da subjetividade em função da organização do cotidiano pela mídia e o modo como a experiência das crianças, dos jovens e dos adultos vem se transformando na sociedade de consumo. Portanto, crianças, adolescentes e adultos alteram suas relações intersubjetivas a partir das influências que a mídia e a cultura do consumo exercem sobre todos nós.
Neste texto, o tema da contemporaneidade será tratado inicialmente a partir das seguintes indagações: o que é infância hoje? Como as crianças e os adolescentes percebem o adulto? Como o adulto fala às crianças e aos adolescentes? O século XVIII inventou a infância. Será que nesta virada de século já podemos dar por sua falta? Será esse um conceito quase obsoleto? Quem são essas crianças e esses adolescentes contemporâneos cada vez mais adultizados?

Postman $(1999)^{2}$ sustenta que, na sociedade americana a linha divisória entre a infância e a idade 
adulta está desaparecendo rapidamente. Acredita o autor que, da mesma forma que a prensa tipográfica criou essa categoria, a mídia eletrônica está fazendo com que ela desapareça. Essas considerações de Postman podem ser estendidas mais amplamente às culturas ocidentais contemporâneas, pois identificamos em nosso contexto social os mesmos sinais que o autor apreendeu da sociedade americana, como por exemplo: crianças se vestem cada vez mais como adultos; as brincadeiras se modificam (especificamente as brincadeiras de rua nos grandes centros urbanos); há um aumento da incidência de crimes envolvendo menores; meninas de 12,13 anos fazem sucesso na carreira de modelo etc. Além dos aspectos mencionados, vale acrescentar que a rotina da criança tem-se transformado, ou seja, pais de classe média se preocupam com a inserção de seus filhos no mercado de trabalho e, em função disso, os introduzem, cada vez mais cedo, em cursos de inglês, informática, esportes...

O tempo compartilhado entre pais e filhos é cada vez mais escasso: trabalha-se cada dia mais para o aumento do poder aquisitivo (e conseqüentemente do consumo), e a mulher tem uma contribuição crescente na fatia produtiva da população, ficando bastante tempo fora de casa. Pais chegam tarde em casa, crianças atarefadas, refeições solitárias ou feitas fora do lar. A família se reúne cada vez menos para conversar sobre o cotidiano... Podemos identificar também como uma característica de nossa sociedade as múltiplas formas de conjugalidade: famílias monoparentais, descasamentos, recasamentos, assim como a crescente incidência de filhos únicos. Portanto, o perfil de família hoje difere do modelo tradicional de família ${ }^{3}$, como pode ser constatado nos depoimentos abaixo ${ }^{4}$.

Ricardo - Hoje em dia, na sociedade, você tem uma crise de paternidade muito grande. Paternidade, que eu quero dizer aí, é o pai e a mãe. Por quê? ... Então essa crise de paternidade, os jovens, a gente tá vendo, as boas maneiras, os costumes, a maneira de se falar, com o pai, com a mãe, com avô, com a avó. Na nossa época a gente pedia benção vovó, benção vovô. Hoje em dia não existe mais nada. (...) O que a gente vê na maioria da sociedade hoje em dia: ela valoriza o ter eo poder. O ser não é muito valorizado. Então a pessoa tem que ter o carro do ano, o melhor apartamento, dinheiro. 'Puxa, eu não sei o que houve, eu dei tudo pro meu filho.' (...) O jovem, a criança hoje em dia, tá carente! Não tem contato com o pai, com a mãe, com o vovô, com a vovó, com o titio, com a titia. É a família que foi colocada em segundo plano. Então, hoje em dia, a gente tem que parar um pouco do ter e do poder e voltar pro ser. É aquilo que eu falei: eu quis botar o meu filho neste colégio porque eu quero que seja uma criança que tenha uma formação de amizade, companheirismo, de fraternidade, de união. Porque a sociedade hoje em dia é totalmente egoísta. É cada um por si e eu não diria nem que é Deus por todos, porque a maioria já não tem muita ligação com Deus. ( pai de um adolescente)
Joana, 13 anos, nos dá sua versão sobre as famílias contemporâneas:

Joana - [Referindo-se a crimes cometidos por crianças e adolescentes, violência nas escolas...] Os pais são aqueles pais que trabalham o dia inteiro, ficam em casa pouquíssimo tempo e mesmo assim nos finais de semana ainda vão trabalhar. Não ficam com o filho. Aí o filho liga pro trabalho: 'olha pai, às nove horas eu tô saindo de casa e não sei que horas que eu volto'. O pai não está nem se preocupando - até porque o trabalho está na cabeça de todo pai e toda mãe. Aí as pessoas já pensam assim: 'vou fazer aquilo pra chamar a atenção do meu pai'... Eu acho que foi até por isso que, certas pessoas, assim, na nossa classe, acontece isso.

A professora também comenta, enfocando especialmente a confusão de papéis, freqüente na família e na escola, e de como a família parece sentirse impotente diante da criança:

Célia - Essa crise de limites ou essa falta de autoridade ou excesso de autoridade, eu percebo assim: tanto a escola não absorve essa função da formação, como a família também está abrindo mão dela. Então eu vejo casos assim: outro dia eu estava vendo uma cena assim meio patética: uma mãe entregando a criança na porta da escola e falando assim [para a professora da criança]: olha, você bota o tênis nele porque comigo ele não quis botar de jeito de nenhum. Tipo assim, é regra da escola, o menino estar na sala, tem que estar uniformizado, ou seja, de tênis. Aí a mãe passa aquilo pra professora porque ela não deu conta daquilo. Eu achei muito engraçado a mãe dizendo que não deu conta. Vai ver que pra ela aquilo não é uma regra e pra professora é. Quem estabeleceu? Eu fiquei olhando pra aquela sensação de impotência da mãe diante de um garoto que devia ter uns quatro anos de idade. Então eu acho que tem essa crise sim, do que que é o limite e que limites a gente tem que dar. E por outro lado uma sociedade que a gente vê que perdeu isso: a questão da ética, a questão do que pode e do que não pode, por onde que a gente segura, por onde que a gente organiza isso aqui. Eu acho que está tudo muito falho. Dentro da escola, como é que a gente está estabelecendo essas regras? Não sei...

Os três depoimentos revelam uma queixa comum nos dias de hoje, ou seja, a dificuldade do adulto no relacionamento com crianças e adolescentes. As preocupações dos pais com os filhos se transformam. Mas, se a criança mudou, o que dizer do adulto?

Para Postman (1999), não só a idéia de infância está em declínio. Paralelamente a esse processo, há também o adulto infantilizado que se alimenta de junkfood ${ }^{5}$, que tem dificuldade em assumir sua prole e familiares idosos, apresentando pouco compromisso com a educação dos filhos. Os limites que separam crianças e adultos estão desaparecendo, pois as diferenças entre essas duas categorias não são enfatizadas.
A educação que um menino recebe dos objetos, das coisas, da realidade físicaem outras palavras, dos fenômenos materiais da sua condição social -, torna-o corporalmente aquilo que é e será por toda a vida. O que é educado é a sua carne, como forma do seu espírito.

Pier Paolo Pasolini

1 Palestra proferida no III Congresso de Psicologia do Desenvolvimento - UFF de 13 a 15 de julho de 2000. Este texto tem como base a pesquisa realizada no âmbito do trabalho intitulado Regras: Conflito e Transgressão. Em Busca da Dimensão Alteritária Infância/ Adulto na Relação Família/ Escola - dissertação de mestrado realizada no Programa de Pós-graduação em Psicologia Clínica da PUC-Rio, por Cristiana Caldas Guimarães de Campos, abril de 2000. Esta pesquisa é parte integrante do projeto "Subjetividade em Imagens: Dialogismo e Alteridade na Produção do Conhecimento Contemporâneo", desenvolvido pelo Grupo Interdisciplinar de Pesquisa da Subjetividade (GIPS), no Departamento de Psicologia da PUC-Rio e UERJ, sob a coordenação da professora Solange Jobim e Souza.

2 o livro de Neil Postman, o Ddesaparecimento da Infância, foi editado nos Estados Unidos em 1982. Em 1994, Postman escreveu o prefácio da edição brasileira, que só veio a ser. lançada em 1999.

3 Ao leitor interessado, ver: Butcher; J. O Casal e a Família sob Formas de Interação. In: Féres-Carneiro, T. (org.) Casale Famúlia - entre a Tradição e a Transformação. Rio de Janeiro. Nau, 1999; 


\section{A infância é uma experiência que praticamente desapareceu, pois se encontra espremida \\ por uma \\ adolescência \\ bastante precoce $e$ uma juventude que se prolonga até os \\ 30 anos. Pelo menos \\ um terço da vida \\ recebe o rótulo de \\ juventude!}

Sarlo

\& Rodrigues, $M$ Recasamento e Recomposição Familiar: Questóes Metodológicas de Linguagem e das Teorias. Psicologia: Teoria e Pesquisa, Brasília; Volume 6, n. 22, 1990 , p. 155-169.

Wagner, A. \& Sarriera, J. Características

Relacionamento do

Adolescentes em Famílias Originais e Reconstruídas. In Féres-Carneiro, T. (org.) Casal e Família - entre a Tradição e a Transformação. Rio de Janeiro. Nau, 1999

4 Os fragmentos são retirados de entrevistas realizadas com adolescentes de 11 a 15 anos, pais e professores que têm filhos elou alunos dessa mesma faixa etária, todos pertencentes às camadas média e média alta da população da cidade do Rio de Janeiro.

5termo utilizado para se referi aos alimentos consumidos como refeições rápidas e de baix qualidade nos centros urbanos.

6 As entrevistas realizadas com pais, professores e adolescentes foram feitas a partir de uma exibição inicial de um vídeo com a duração de aproximadamente oito minutos. Os sujeitos entrevistados assistiam a uma montagem com fiagmentos de noticiários, filmes, entrevistas e desenhos animados retirados das programações televisivas.

Em seguida o diálogo se estabelecia no grupo direcionado pelo conteúdo apresentado pelas imagens do vídeo. Essa estratégia de entrevista foi extremamente promissora, pois permitia atualizar a experiência de ver TV em um contexto diferente do habitual. A intenção foi desencadear, durante a
Sarlo (1997) sinaliza que a infância é uma experiência que praticamente desapareceu, pois se encontra espremida por uma adolescência bastante precoce e uma juventude que se prolonga até os 30 anos. Pelo menos um terço da vida recebe o rótulo de juventude! Alguns autores buscam uma explicação para esse fato a partir das transformações radicais que vêm sendo operadas no cotidiano pela circulação das informações e o acesso crescente às novas formas de tecnologia em permanente expansão.

Segundo Postman (1999), após a invenção do telégrafo por Morse, a informação passou a ter um caráter anônimo, descontextualizado, tornando as diferenças entre culturas irrelevantes. "O telégrafo criou um público e um mercado [não só] para a notícia fragmentada, descontínua e essencialmente irrelevante, que até hoje é a principal mercadoria da indústria da notícia" (p. 85). O telégrafo foi o precursor das mudanças que o seguiram: prensa rotativa, fotografia, telefone, cinema, rádio, TV (e, mais recentemente, a Internet), tornando impossível o controle da informação, modificado em sua forma, havendo hoje uma preponderância de imagens. Tais mudanças trouxeram conseqüências para a infância, retirando da família e da escola o controle da informação, alterando o tipo de acesso das crianças e dos adolescentes à informação. A imagem da televisão, por exemplo, está disponível a todos, independente da classe ou idade. "Na TV, tudo é para todos" (p. 93). Não há distinção criança/adolescente/adulto/idoso ou indiferenciação quanto a seu acesso. É só ligar a televisão.

A mídia invade nosso cotidiano. A criança e o adolescente de hoje não conheceram o mundo de outra maneira - nasceram imersas no mundo com telefone, fax, computadores, televisão, etc. TVs ligadas a maior parte do tempo, assistidas por qualquer faixa etária, acabam por assumir um papel significativo na construção de valores culturais. A cultura do consumo molda o campo social, construindo, desde muito cedo, a experiência da criança e do adolescente que vai se consolidando em atitudes centradas no consumo.

Ricardo - Os filhos, as crianças de uma maneira geral, estão sendo produtos daquilo que eles estão recebendo. E o pai e a mãe - a família em si - eles têm quantitativamente tempo de contato junto com os filhos muito menor do que a mídia. Então o que eles [os filhos] recebem da mídia é aquilo que a gente acabou de ver [Ricardo se remete ao vídeo que passamos no início da entrevista]: é violência, é explosão, falta de hábitos.

O hábito de ver televisão se encontra incorporado ao cotidiano de crianças, adolescentes e adultos.

Viviane - É uma coisa que vicia... Você chega em casa já vai na televisão. Vou tomar banho e deixo a televisão ligada. Até pra dormir - dorme escutando a televisão. $\hat{E}$ por causa do ruído...
Joana - Eu tenho esse vício. Eu chego em casa, eu janto, tomo banho e já deito pra ver televisão. É normal, a gente janta vendo televisão, a gente até toma banho escutando a televisão que o pai deixou ligada. Énormal, até porque desde os três anos todo mundo vê televisão. Você já está acostumado (adolescente).

Marcela - Já é hábito isso. É a mesma coisa que você tomar banho, escovar os dentes, é um hábito você ver televisão. É raríssimo... Eu conheço poucas pessoas que não vêem televisão, que não têm televisão em casa. É difícil (adolescente).

Diogo - É difícil eu dormir assim sem ver TV. Eu sempre pego a TVe aí tinha um negocinho chamado sleeptime. Você bota lá o tempo que você quer e depois ela desliga sozinha. Agora toda a noite eu não consigo dormir sem ver TV. Não posso dormir... Toda a noite eu vejo TV (adolescente).

Postman conclui de forma drástica sua análise sobre a TV:

"Podemos concluir, então, que a televisão destrói a linha divisória entre infância e idade adulta de três maneiras, todas relacionadas a sua acessibilidade indiferenciada: primeiro, porque não requer treinamento para apreender sua forma; segundo porque não faz exigências complexas nem à mente nem ao comportamento, e terceiro porque não segrega seu público. Com a ajuda de outros meios eletrônicos não impressos, a televisão recria as condições de comunicação que existiam nos séculos quatorze e quinze. Biologicamente estamos todos equipados para ver e interpretar imagens e ouvir a linguagem que se torna necessária para contextualizar a maioria dessas imagens. Onovo ambiente midiático que está surgindo fornece a todos, simultaneamente, a mesma informação. Dadas as condições que acabo de descrever, a mídia eletrônica acha impossível reter quaisquer segredos. Sem segredos, evidentemente, não pode haver uma coisa como infância" (p. 94).

Para esse autor a idéia de infância está diretamente relacionada à possibilidade de haver segredos e à vergonha do adulto frente à criança. Quando tudo é dito e, principalmente mostrado via imagem, que diferença se estabelece entre adultos e crianças? $\mathrm{O}$ pudor em falar de certos assuntos, de determinada maneira, parece não fazer mais parte do nosso cotidiano. Como se encontra esse processo de autocontrole na sociedade midiática e imagética, já que a mídia parece desafiar a autoridade do adulto, questionando o lugar de saber que este ocupava? Essa é uma questão importante e que merece ser levada em consideração. Embora a resposta não seja simples nem imediata, vale refletir sobre o papel da mídia, especialmente o da publicidade, na 
construção de novos padrões identitários para crianças, jovens e adultos a partir dos signos de prestígios fornecidos pela cultura do consumo. A publicidade se utiliza de modo indiscriminado da imagem da criança, do jovem ou do adulto para vender estilos de vida e mercadorias, criando uma nova fórmula de estratificação social e cultural. O valor das mercadorias e dos objetos substitui o valor do homem, ele próprio transformado em mercadoria, definindo uma nova ética no campo das relações sociais.

Nos dias de hoje, há cada vez mais a preponderância dos processos de consumo, fazendo com que os sujeitos sejam levados a identificar-se com coisas e objetos que os levam a diferenciar-se dos demais, como também a discriminar e hierarquizar grupos sociais. Baudrillard (1995) esclarece que não é o consumo que se organiza em torno das diferenças individuais, mas, sim, estas, assumindo a forma de personalização, é que se organizam em torno de modelos comunicados pelo sistema de consumo. Para esse autor, existe inicialmente a lógica da diferenciação social e, depois, a manifestação organizada das diferenças individuais. Com isso, o sistema promove a anulação das diferenças "reais" e transforma as pessoas em seres contraditórios através da produção industrial da diferença. Em suma, o que prepondera é a ilusão de que podemos realizar escolhas autênticas, pois, de fato, todas as escolhas já estão previstas pelo sistema. $\bigcirc$ processo de construção da identidade na cultura de consumo apresenta-se como cambiante, fluido, fragmentado e parcial. Objetos e mercadorias são usados para demarcar as relações sociais e determinam estilos de vida, posição social, além da maneira de as pessoas interagirem socialmente. "Isto faz com que tais mecanismos culturais tenham o papel de estipular a natureza da experiência emocional e social que regerá o contexto entre os diversos grupos sociais" (Rabello de Castro, 1995: p.222).

Canclini (1997) mostra-nos como a maneira de consumir acabou por alterar as possibilidades e as formas de exercer cidadania. As identidades contemporâneas se configuram no consumo, dependendo daquilo que se possui ou do que se pode vir a consumir. Há um descontentamento com o que se tem, próprio do mundo globalizado, que "supõe uma interação funcional de atividades econômicas e culturais dispersas, bens e serviços gerados por um sistema com muitos centros, no qualé mais importante a velocidade com que se percorre o mundo do que as posições geográficas a partir das quais se está agindo" (p. 17). Esse descontentamento provém da fugacidade, da obsolescência. Tudo se torna obsoleto a todo instante.

Nós nos encontramos em um novo cenário sóciocultural: as instituições públicas, os órgãos locais e nacionais estão perdendo seu poder para conglomerados empresariais transnacionais; os padrões de convivência urbana estão se transformando; há uma reelaboração do que é próprio de uma cidade ou de uma nação em função da globalização e, conseqüentemente, o sentido de pertencimento e de identidade se modificam radicalmente. Para Canclini, o processo de globalização pode ser resumido na transposição de identidades modernas - territoriais e monolinguísticas, para identidades pós-modernas - transterritoriais e multilinguísticas. E Beatriz Sarlo (1997) complementa:

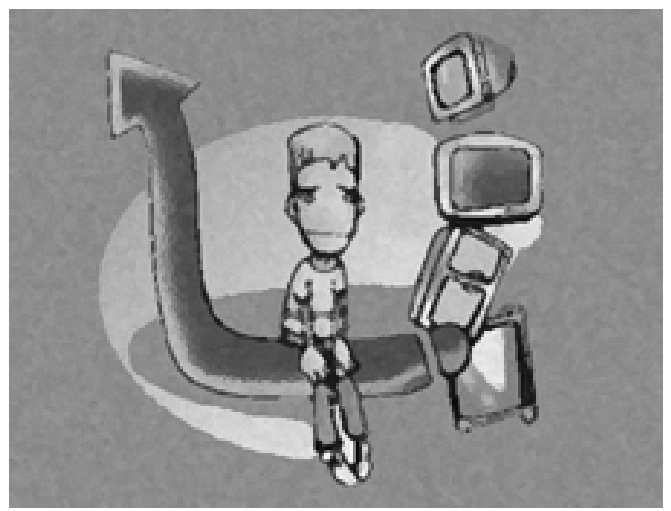

(Referindo-se aos objetos) "Tornaram-se tão valiosos para a construção de uma identidade, são tão centrais no discurso da fantasia, despejam tamanha infâmia sobre quem não os possui, que parecem feitos da matéria resistente e inacessível dos sonhos. Frente a uma realidade instável e fragmentária, em processo de velocíssimas metamorfoses, os objetos são uma âncora paradoxal, já que ela mesma deve mudar o tempo todo, oxidar-se e destruir-se, entrar em obsolescência no próprio dia de sua estréia" (p. 30).

O mercado nos ilude prometendo o ideal de igualdade e liberdade. Ele escolhe quem fará parte do seleto grupo que pode consumir, gerando exclusão. Em seu discurso, reforçado pelos meios de comunicação, todos somos iguais. As mercadorias têm que ser novas, da moda. Devem captar as mais insignificantes mudanças, que constituem o mito da novidade permanente que impulsiona crianças, adolescentes e adultos. $\bigcirc$ consumidor, apto à entrada no mercado, é uma espécie de colecionador às avessas, colecionando atos de exposição. Ele sabe que os objetos se desvalorizam quando os agarramos. Uma vez adquirida, a mercadoria perde sua alma. Não há objeto que aplaque a falta daquele que consome haverá outro que chama sua atenção.

Devemos voltar, neste momento, à nossa indagação central: qual o lugar da infância na cultura do consumo?

Ora, a infância não se oferece mais como categoria que proporciona felicidade e inocência (Sarlo,

"Podemos concluir, então, que a televisão destrói a linha divisória entre infância e idade adulta de três maneiras, todas relacionadas a sua acessibilidade indiferenciada: primeiro, porque não requer treinamento para apreender sua forma; segundo porque não faz exigências complexas nem à mente nem ao comportamento, e terceiro porque não segrega seu público.

Postman 
1997). A infância muda seu lugar social: sai do lugar de inapta, incompleta, para o de consumidora, transformando sobremaneira sua forma de inserir-se no mundo. Ao mesmo tempo, a criança e o adolescente se encontram num lugar dúbio, pois são vistos ainda em sua incompletude - necessitam da escola para a aprendizagem legitimada pela sociedade e, paralelamente, encontram-se mais aptos que seus pais e professores para lidar com as novas tecnologias da vida cotidiana (Rabello de Castro, 1998).

Marcela, uma adolescente, diz o seguinte sobre a infância contemporânea:

Marcela - Eu acho que a criança de hoje ela está muito precoce pras coisas. Tem muita coisa que eu acho errado, por exemplo: uma garota de quatro anos botar um shortinho da Carla Perez, topizinho... Eu acho isso horrivel! Eu acho muito precoce! Pois é, eu acho que é influência da televisão, é achar bonito. Ninguém mais acha bonito Sítio do Pica-pau Amarelo, que era uma coisa educativa. Hoje todo mundo... Vamos ver o programa do Raul Gil, do Faustão, que vai ter a bunda lá da Carla Perez. Gente! Eu acho que poderia trabalhar essa coisa precoce da criança de hoje mais voltada pra outro lado, entende? Tem criança de cinco anos hoje que está dançando? Beleza! Vamos dançar! Então vamos botar numa aula legal, em vez de estar dançando a música do Tchan.

O depoimento de Marcela nos conduz a uma outra cena, ou seja, o papel da escola. Indagar sobre o papel da escola e refletir sobre a função da educação hoje é tarefa da maior relevância. Beatriz Sarlo (1997) acredita que a escola teve seu prestígio debilitado. Empobrecida material e simbolicamente, a escola não está sabendo como ser atraente e sedutora para uma infância imersa na cultura audiovisual. Porém não se trata apenas de uma questão de aparato técnico, mas, sim, de uma mutação cultural. Permitido e proibido encontram-se em crise e, conseqüentemente, a autoridade também, pois perdeu seu aspecto terrível e intimidatório. Essa autora chega a nos atemorizar, afirmando que "onde antes se podia enfrentar a proibição discursiva, hoje parece restar só a polícia" (p. 40). A escola poderia beneficiar-se ao incorporar as habilidades de seus alunos, apropriando-se da velocidade do videogame, da superposição de imagens e dos conteúdos da mídia. "A aprendizagem é um processo de aquisição de diferenças, exploração do estranho, no qual a primeira lição consta das habilidades necessárias para aprender e das condições psicomorais (digamos assim, à falta de melhor termo) imprescindíveis" (p. 114 115).

O depoimento de uma professora nos fala também da necessidade de transformação da escola em função das novas características da sociedade dita, por alguns, pós-moderna:
Vânia - A escola vai ter que se transformar. Porque a escola não vai ser só lugar de conteúdo, porque o conteúdo que a gente recebe lá fora é muito maior do que o da escola. Ela não está conseguindo ainda porque ela está nos moldes de cinqüenta anos atrás. Uma aula em cinqüenta minutos, compartimentada.(...) Eu acho que vai ter que haver, aos poucos, uma modificação. Eu acho que hoje em dia, a principal função da escola é fazer o aluno pensar e pensar sobre tudo. Não só sobre conteúdo da disciplina, mas pensar nas suas atitudes, quais são os valores que mobilizam a sociedade para transformar e para poder modificar essa sociedade para melhor.

Percebemos que a escola, por outro lado, acaba por tentar abarcar responsabilidades que eram outrora da família, como diz outra professora:

Mônica - Cada vez mais eu sinto isso: que a educação fica cada vez mais nas nossas mãos, educação de um modo geral: o educar, conteúdo, passar conteúdo, hábitos..

Controvérsias à parte, de uma forma geral a opinião de pais, professores e adolescentes coincide em uma questão: identifica uma forte influência da mídia (e, para alguns, dos jogos eletrônicos também) na construção de valores e na internalização destes pelos sujeitos. Observam que os valores que têm sido veiculados pela mídia, muitas vezes, não se coadunam com os que a família e a escola consideram como "legítimos" e que devem ser passados às crianças e adolescentes.

Identificam que a TV é uma forte presença na vida de todos e muitos admitem que dormem com ela ligada, assumindo um rótulo de vício, mas é interessante verificar que, ao mesmo tempo, esses mesmos grupos, em alguns casos, possuem uma visão crítica, ora culpabilizante (responsabilizando a mídia e os jogos eletrônicos por todo tipo de transgressão às normas sociais), ora relativizante sobre o papel que a mídia tem exercido em nossa sociedade na formação de valores. Com freqüência ela é apontada como desencadeadora de violência nos grandes centros urbanos.

Os adolescentes ressaltaram também uma grande influência da mídia nos gostos e escolhas e dizem o seguinte:

Viviane - Outra coisa que influencia muito a criança menor é vídeo game. Por exemplo, tem muitos jogos de violência... Etelevisão também, esses filmes de porradaria, toda hora... muito... Eu acho que tem uns joguinhos, que são aqueles que você ganha uma arma e tem que ir atirando nos caras e seu objetivo é matar. Então você fica com aquela arma e fica neurótico pra matar. Todas as crianças pequenas de quatro, cinco anos, já tão começando a jogar vídeo games e vão começar a pedir pro paicomprar arma, e quando crescer mais, estar com uma arma de verdade. 
Joana - E tem até um garoto no colégio que saiu metralhando todo mundo e descobriram que no computador dele tinha um jogo - que até o pessoal aqui do colégio tem - que é uma arminha assim Imostranos, com o gestol e o cara sai matando todo mundo. $E$ descobriram que o último jogo que ele fez antes de matar todo mundo e de se matar a si próprio, se matar, tinha uns corpos pendurados de cabeça pra baixo numa sala. Todos estranhos assim... Concluíram que o garoto estava sendo influenciado pelo vídeo game também.

(...) Joana - Porque uma criança que está passando no canal, vê uma mulher dançando no Ratinho, o Ratinho dando porrada nas pessoas - porrada que eu digo pode até ser de brincadeira - mas passa e é uma influência pras crianças. Porque ela tá passando ali, ela pára pra ver, é como se fosse uma tentação. Ela passa por ali, ela tem que ver. Tem que parar e tem que ver.

(...) Marcela - Tem gente que gosta justamente por isso: está passando a televisão e aí pára. Ah, legal isso! Vou continuar vendo! As pessoas têm o hábito: acabou de chegar em casa, vou ligar a televisão.

Professores também acreditam que a mídia e os jogos eletrônicos exerçam uma forte influência sobre as crianças e os adolescentes. Uns atribuem à escola a função de criticar o conteúdo do que é visto na $T V$; outros ressaltam que não têm como fazer um embate a esses veículos, ponderando que, neles, há coisas boas e ruins. Vêem como possibilidade formadora trabalhar, com os alunos, a presença de diferentes olhares e concepções de mundo veiculados pela TV. Vale também ressaltar que eles dão ênfase ao papel da família, que deveria acompanhar mais os programas e/ou jogos que os filhos assistem e/ou jogam.

Vânia - É que a mídia é muito forte. (...) A criança fica exposta à imagem. A imagem, ela tem uma força muito grande. Então... E aí o que fica disso? Eu acho que a família tem que estar atenta, assistir junto, discutir, mas isso leva tempo.(...) Com a televisão, uma evolução da imagem e de tudo de apertar o botão, comunicação... Mudou completamente. A informação chega rápida, fragmentada... você muda. (...) Eu não gosto de ver só por um lado não [a mídia]. Eu acho que existem bons programas e existem programas ruins. Existem coisas boas e ruins. (...) E o papel da gente é de estar fazendo esse contraste (professora).

Mário - Gente, é uma luta inglória! [luta contra a mídia]. Lutar contra qualquer coisa... Eu acho isso completamente absurdo! O que a gente pode, é estar assim, dialogando diretamente com a mídia. É difícil demais... A partir de você estar possibilitando diversos olhares sobre o mesmo quadro, que ele vai olhar aquilo com olhar crítico. Eles falam de um jogo de computador um tal de knão sei o quê... Kmargedon. Foi até proibido, de tão violento que é... Eles [alunos] estavam falando: 'ah, porque foi proibido'. Vocês gostavam de jogar'? [Mário perguntando aos alunos] 'Gostávamos'. 'Mas porque vocês gostavam de jogar? O que tinha de legal nesse jogo?' Porque isso nunca se pergunta (professor).

Mário destaca as possibilidades de gerar um trabalho crítico com a mídia através da problematização dos conteúdos apresentados nos programas, ouvindo o que crianças e adolescentes têm a dizer sobre o que assistiram, sobre o que gostaram e porque gostaram, percebendo as crianças e os adolescentes como sujeitos capazes de elaborar críticas sólidas e bem fundamentadas quando estimulados a tal postura.

João - Uma família onde as pessoas trabalham e o adolescente fica em casa ou na rua e tem acesso a filmes violentos, exemplos péssimos de como você se comportar com relação ao outro e isso tudo leva a uma influência muito maior. (...) Ficou claro a questão dos vídeos games, como a violência virou uma mercadoria, um atrativo. Os próprios filmes (...) então é uma luta constante que você tem que construir (professor).

Os professores não atribuem à mídia um papel maniqueísta. Apesar das críticas, percebem pontos negativos e positivos nesse veículo e identificam possibilidades de trabalho com seus alunos a partir dela; ao mesmo tempo, explicitam que a demasiada exposição a imagens violentas pode trazer influências negativas na formação dos alunos. É interessante analisar que, novamente, a violência na vida real emerge como tema associado à mídia.

Mário - Se tem uma coisa que a mídia não é, é não intencional. Porque você precisa o quê? Você tem uma conformação social que é a do indivíduo. A sociedade é individualista. Quais são as qualidades que você precisa desenvolver pra viver numa sociedade que você tem que brigar contra todo mundo: agressividade, medo do outro, desconfiança e é isso que a gente trabalha. $\hat{E}$ muito intencional. Esses filmes que passam hoje na sessão da tarde. Quando a gente tinha quinze anos, passava depois de onze horas. Não é gratuito isso! Porque o grande jogo da mídia é dizer assim, que ela faz o que o público pede. Mas quem faz o público? (...) São dois modelos de sociedade que são antagônicos. A gente tá falando de um modelo de sociedade coletiva e todo o nosso processo político e econômico é de uma sociedade individualista, que vai utilizar os seus elementos de reprodução e a mídia pra desenvolver as características que ela precisa. Antigamente, o sujeito dava um tiro e o cara morria. Não precisava aparecero buraco... (professor).

Para Mário, é evidente a intencionalidade da mídia, que se encontra a serviço de um modelo individualista de sociedade, ou seja, produzimos indivíduos dotados de valores que sustentam essa conformação social. Os pais identificam a mídia e os jogos eletrônicos como meios que passam valores diferentes dos pregados por eles. Acreditam também que os programas são violentos e que, por vezes, faz-se
"A aprendizagem é um processo de aquisição de diferenças, exploração do estranho, no qual a primeira lição consta das habilidades necessárias para aprender e das condições psicomorais".

Sarlo 


\section{"A saída narcísica leva o cidadão a buscar a felicidade na proteção de suas casas, munidos de artefatos de consumo cada vez mais sofisticados, mas cada vez mais descrentes de uma saída coletiva"}

Jurandir Costa necessário intervir. Outros discordam, acreditando que os adolescentes devem assistir a tudo, evitando a censura que poderá estimular, ainda mais, a curiosidade em relação ao que deveria ser proibido.

Andréa - ... Eu acho que está bastante complicado. Os filmes, os programas de uma maneira geral, estão muito permissivos. Há banalização do sexo e da violência. Éa banalização mesmo (mãe).

Rejane - Mas eu deixo ela [Júlia, filha] ver, senão ela fica fantasiando. O que será que tem lá.

Cecília - Eu já não deixo... Está vendo... Eu já não deixo, às vezes passa, é claro. 'Ali só tem besteiras, vamos ver uma coisa melhor' [Cecília diz ao filho].

Cássia - O André [seu filho] gosta muito daqueles filmes de luta. Aquelas lutas... Ele adora aquilo. Agora está melhorando um pouquinho (mães).

Antônio - Outro dia, uma gravação de um sujeito se masturbando numa ponte em São Paulo, olhando para as pessoas do outro lado [no programa do Ratinho]. Eu falei: 'Parou, parou, mudou, mudou. Não pode, não pode' (pai).

Ricardo - A televisão bombardeia com tudo que é o contra valor. O valor que a gente tinha da família está de cabeça pra baixo hoje em dia. É justamente o contra valor. É tudo que é programa, seriado, esses pacotes que vêm dos Estados Unidos: éviolência, é um passando a perna no outro, é dinheiro, é poder, quer dizer, isso aí não vai levar à fraternidade nunca (pai).

Esses depoimentos nos remetem ao que foi anteriormente dito por Postman (1999), quando apontava para o sentimento de vergonha como um dos indicativos do desaparecimento da categoria infância. Notamos a tentativa de alguns pais em manter esse sentimento presente, fazendo uma seleção do que pode ou não ser visto por seus filhos. Observamos que os depoimentos apresentados convergem ou divergem, mas os valores pregados pela família e pela escola, no nível do discurso, se coadunam. Fica evidente uma crítica à sociedade, ao predomínio dos processos de consumo, onde o ter vale mais que o ser. Uma sociedade individualista e violenta, uma sociedade em crise.

Jurandir Freire Costa (1994;1995), analisando o perfil da sociedade brasileira, identifica quatro atributos que a compõem: o cinismo, a delinqüência, a violência e o narcisismo. As causas da violência no Brasil estão, segundo esse autor, relacionadas à formação de nossa sociedade. Ele identifica, basicamente, duas formas de violência: a violência estrutural, de base, que advém do caráter autoritário da formação de nosso país e é expressa na desigualdade dos níveis de vida, na fome, hierarquizada que mantém seus privilégios, e a

violência urbana, da degradação dos valores - o que faz com que uma sociedade se mantenha ou não coesa: o apreço à preservação dos valores que as elites intelectuais, políticas e culturais assumem. Já cinismo é uma característica que transparece, por exemplo, na indignação com deputados corruptos, porém, concomitante e paradoxalmente, no dia-a-dia, gestos, palavras e ações, como por exemplo ultrapassar o sinal vermelho, acontecem como situações admissíveis. Com isto se estabelece uma cisão entre duas esferas de valores que parecem não se chocar.

Como as leis, as regras são convenções que garantem nossa sobrevivência a delinqüência apresenta-se, desse modo, como uma cultura suicida, na medida em que nossos instintos não nos protegem. A transgressão à regra dá uma ilusão, em nossa sociedade, de que podemos ficar impunes. $E$, na inexistência de um mundo de valores, tudo é possível, já que desaparece a possibilidade da reflexão ética nesta cultura da razão cínica. Como instrumento para garantir a imunidade à delinqüência, o narcisismo se apresenta como possibilidade. EJurandir Costa (1995) sentencia: "Asaída narcísica leva o cidadão a buscar a felicidade na proteção de suas casas, munidos de artefatos de consumo cada vez mais sofisticados, mas cada vez mais descrentes de uma saída coletiva" (p.15).

As regras, pautadas pelo ideal narcísico, acabam por não garantir uma relação de alteridade entre crianças, adolescentes e adultos. O outro não tem mais capacidade de me alterar. Não é igual a mim.

"Quando o ser humano não tem mais a regra subjetiva que lhe faça ver no outro um semelhante, ele não experimenta pelo outro nenhuma preocupação, nenhuma consideração. O outro é um estranho. (...) Como eu não tenho critério de reconhecimento, como eu não sou formado para dizer que aquele é igual, eu não posso me identificar na dor e no sofrimento e nem na dignidade com o outro e aí eu não vou me importar" (Jurandir Freire Costa, 1994: p. 12).

O depoimento de Claudia confirma as palavras indignadas de Jurandir:

Cláudia - Mas eu não sei, me parece assim, que quanto maior o padrão de vida das crianças, me parece que os valores que ficam um pouco mais deturpados. (...) Eu só observo a agressividade entre os alunos. Eu vejo que ao invés deles tentarem caminhar juntos que seria mais fácil de repente, de mão dadas, eles vão cada um por si. Eu me safando tá ótimo. Eu não sei, talvez seja a própria sociedade (mãe).

Nesse sentido, a possibilidade de construção de uma sociedade que leve em consideração esse outro se daria por ações pontuais em cada setor onde é possível agir. Jurandir Costa salienta que a escola, assim como a mídia - tantas vezes tão criticada e tida 
como vilã - pode ter uma grande função nesse processo, e justifica: "O fato é que através da escola você atinge a multidão de novas gerações. Sabemos o peso que a escola tem na formação da criança e do adolescente. Precisamos ter professores convencidos disso..." (p.12). Por isso, devemos reativar e revitalizar valores, educar as novas gerações e realizar um permanente debate sobre a ética.

O que temos constatado é que essa crise estimula iniciativas para mudanças e a escola tenta oferecer um novo modelo de relações, mas defronta-se com muitas dificuldades.

Vânia - Mudou tudo, tudo. Primeiro a valorização do ter em relação ao ser.(...) Essa é uma situação que a gente vivencia hoje de uma forma muito confusa. As famílias, elas não atuam da mesma maneira. Então não há um consenso... Antigamente havia um consenso maior do certo, do errado, do que se deveria ou não deveria se fazer. (...) A sociedade consumista do jeito que tá, promovendo uma ilusão do ter mais do que o ser... Então, são várias questões. (...) Nesses vinte nove anos que eu tenho de profissão, eu vejo que a gente vai vendo a mudança que houve das crianças, dos jovens, nessa questão da violência. Eu percebo que eles não acham violento determinadas brincadeiras. Eles brincam. Acham que é brincadeira. Então por exemplo, empurrar o colega, cair em cima do outro, apertar o peito do outro para não respirar, é brincadeira, não é uma violência na concepção deles (professora).

Fernanda - Eu reconheço essa realidade que eles conhecem porque eu estou vivendo essa realidade também. Um mundo de violência, um mundo individualizado, um mundo competitivo (professora).

O indivíduo hoje vale pelo que possui, pelo que veste, pelos objetos que consome.

Ricardo-Então, o que aconteceu? Quebrou-se aquela história toda de liberdade total de leis e não se colocou nada no lugar. Então a sociedade hoje em dia está vivendo essa crise de paternidade, e não se colocou nada no lugar, ou seja, o jovem não tem limite. A maioria deles quer ter o carro do ano, quer viajar pra todo lugar, só quer saber de dinheiro... É egoísta (pai).

Vilma - Elas [meninas adolescentes] se preocupam com a roupa se tem... A roupa pode ser porcaria, mas se teve um nome aqui Calvin Klein, Yes ou não sei quê... Pra elas isso é importante. Mas isso é o meio, eu tenho certeza. Na minha casa não é assim. Eu não tenho esse padrão, nós não temos condição financeira (mãe).

A mudança na sociedade em que vivemos afeta não somente os valores que assumimos, mas também a temporalidade e a concentração para uma determinada atividade. Há um bombardeio de informações que afeta a rotina dos adolescentes e se impõe pela rapidez com que as coisas acontecem. Um novo ritmo impera. A escola identifica essas mudanças, mas ainda parece haver dificuldade em conjugar o ritmo do tempo na escola e a ritmo do tempo vivido pelo aluno fora dela.

João - Ele [aluno] tem dificuldades porque ele está adestrado, vamos dizer assim, a ter muitas informações num curto espaço de tempo - essa é a temporalidade dele. Então, quando você, em sala de aula, quer aprofundar mais uma discussão qualquer... Vamos imaginar uma questão agrária, vamos imaginar isso... Você quer discutir um pouco mais a fundo isso com jornais, com revistas, com os capítulos do livro... Pra chegar a um grau de concentração, você tem que elaborar muito bem, porque esse não é o ritmo que é imprimido no dia a dia. No dia a dia dele é rápido, sai daqui vai pra lá, daqui a pouco tem que ir pro judô. Então é uma outra dinâmica. Nós percebemos isso em sala de aula, a questão da concentração (professor). Cecília - Eu acho que a gente não pode parar, as

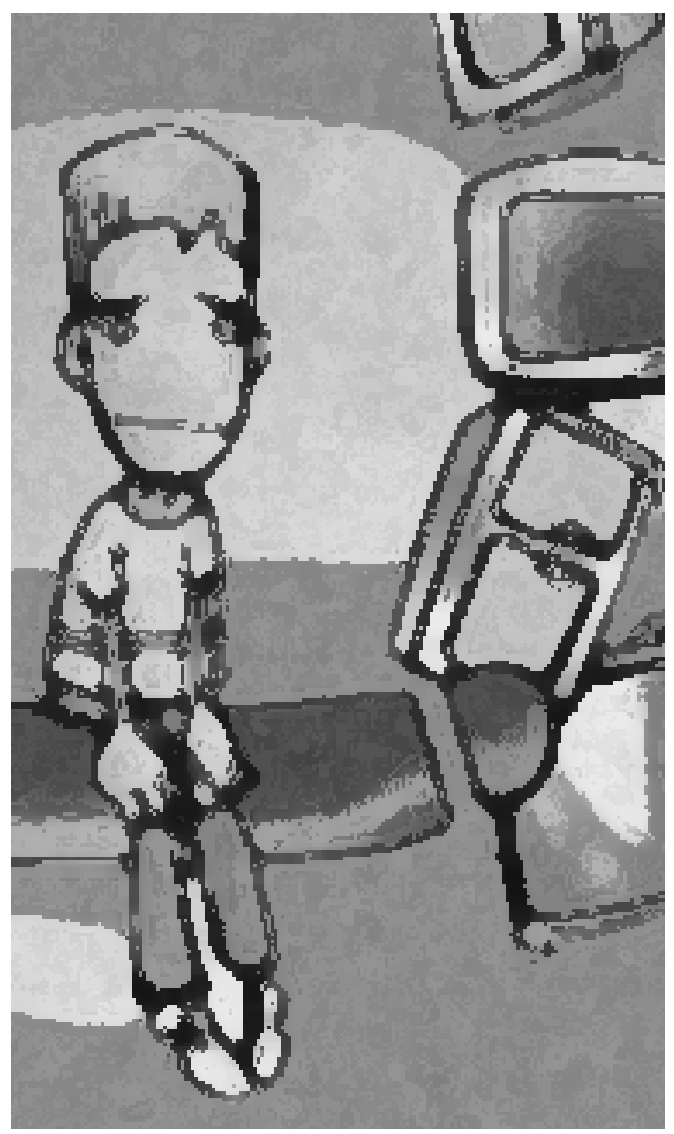

"Mudou tudo, tudo. Primeiro a valorização do ter em relação ao ser.(...) Essa é uma situação que a gente vivencia hoje de uma forma muito confusa. As famílias, elas não atuam da mesma maneira. Então não há um consenso... Antigamente hovia um consenso maior do certo, do errado, do que se deveria ou não deveria se fazer. (...) A sociedade consumista do jeito que tá, promovendo uma ilusão do ter mais do que o ser... "

informações são muito rápidas. Porque o meu filho só tem onze anos e eu não posso parar. As informações vêm de todos os canais. Você nem dá conta de ver tudo, tanta informação. Então é selecionar o que você precisa ler de fato, se organizando realmente (mãe).

A violência nos grandes centros urbanos é outro aspecto ressaltado e, em decorrência disso, as famílias 
se enclausuram em condomínios, shoppings, etc. Crianças e adolescentes adiam a sua independência e a autonomia do jovem fica comprometida pela necessidade de se garantir a segurança física. A juventude se prolonga na idade adulta instituindo a adolescência sem fim.

Antônio - Meu filho está com dez anos e: sai? Não sai? Vaina esquina? Não vai? Eu passei minha infância inteira na rua. Minha infância inteira foi na rua descalço jogando futebol (pai).

Sônia - Mas a gente vive com a violência... No Jornal Nacional, não há como, a fala é diária. (...) É um contato que as crianças têm diário de uma realidade que a gente tem que passar no sentido de que eles saibam se proteger. E até aceitar essa idade de dez anos querer sair sozinho. 'Eu quero ir ali na esquina sozinho!' Eu acho que vai ter que ir, mas ele tem que estar sabendo dos riscos (mãe).

"quanto mais o homem compreende que é determinado (reificado), mais perto está de compreender também, e de realizar, a sua verdadeira liberdade"

Bakhtin
Em um curto espaço de tempo, mudanças rápidas e bruscas aconteceram no contexto em que vivemos. As novas tecnologias, o consumo e a influência da mídia marcam, modelam e constróem as subjetividades contemporâneas. Se, por um lado, os adultos romperam com a rigidez da educação à qual foram submetidos, por outro, na tentativa de se adaptarem ao mundo atual, sentem-se, por vezes, inseguros quanto à forma de agir com os filhos, apresentando dificuldades em lidar com conflitos.

Sonia - É muito difícil, porque chega uma hora... E quando ele [filho] questiona isso [como os pais estão educando], eu penso: será que eu estou sendo rígida? Essa insegurança bate mesmo. Será que é isso? É. Não... (mãe).

Um outro aspecto importante é que a mídia apresenta um lugar de destaque na fala de pais, professores e adolescentes. Entretanto, mesmo criticando seu papel na formação de valores, é freqüente os adultos estabelecerem castigos ou punições que envolvem a proibição de assistir TV, conferindo, com essa atitude, uma supervalorização a esse veículo de entretenimento. Em suma, embora os adultos, os jovens e as crianças tenham consciência de que somos profundamente marcados pela cultura do consumo, pais e professores acabam utilizando os bens de consumo como um meio para valorizar ou punir comportamentos desejados ou não desejados nas crianças e nos adolescentes. Certamente essa atitude acaba por reforçar aqueles mesmos comportamentos criticados por eles. Desse modo, a manipulação veiculada pela mídia e pela cultura do consumo é sustentada nas relações intersubjetivas no âmbito da família.

Entrevistador - Eo que acontece quando você faz uma coisa que não pode, o que acontece?
André - Eu tô há três semanas sem ver TV.

Cássia - Você não pode ver televisão porque infringiu uma regra. Hoje você não vai poder mexer, então não vai ao passeio. Não vai ao cinema. [ela diz ao filho diante de uma transgressão] Ah, o André ficava uma fera, ficava uma fera. Dá chute. A única coisa que... é cortar uma coisa que ele gosta. Ver televisão, jogar no micro, ir ao cinema. Essas coisas que ele adora, então eu tento cortar, por aí (mãe).

Vilma - Agora lá em casa tem uma regra sobre dinheiro. Nós não damos mesada. Isso é em função da nota. É uma regra que funciona. E tem uma tabela de nota até tanto ganha tanto, de tanto, ganha tanto. Então chegou o boletim vem a hora mesada. Aí a gente vai fazer a nota que chegar. Dessa nota pra baixo vocês me pagam tanto. Então vamos dizer, vinte reais acima de nove, oito a nove, dez reais ganha, de oito pra baixo me paga cinco, de sete pra baixo me paga dez. Assim faz uma conta de chegar. E eles procuram porque como não tem dinheiro fácil, eles não têm aquele dinheiro garantido.

Quando conquistamos plena consciência de que nossas atitudes e palavras são ações que definem, alteram e determinam as práticas sociais somos, então, capazes de alterar os rumos da nossa história na grande temporalidade. Citando Bakhtin (1992), podemos reafirmar que "quanto mais o homem compreende que é determinado (reificado), mais perto está de compreender também, e de realizar, a sua verdadeira liberdade" (p. 379).

Este texto pretendeu oferecer uma base sólida para uma compreensão mais profunda das implicações éticas de nossas atitudes no cotidiano. Contamos, assim, com muitas vozes - fragmentos das falas de adultos, crianças e jovens, além de reflexões teóricas retiradas de diversos autores - para orquestrar nossas indagações, e esperamos ter desencadeado no leitor o desejo de participar deste diálogo e de construir novas visibilidades para o tema em questão. Esta proposta visa à elaboração de um discurso mais sistematizado sobre a mídia e a cultura do consumo, pautado nos textos escritos e falados que circulam entre nós, e a partir daí oferecer subsídios para conquistarmos uma compreensão cada vez mais sólida e reflexiva sobre a constituição da subjetividade de crianças, jovens e adultos na contemporaneidade. $\mathrm{Na}$ medida em que a construção do saber se dá sempre na interlocução entre diferentes vozes que se posicionam no mundo e sobre o mundo, este texto pretende ser mais uma oportunidade de diálogo e conhecimento para elucidar os desafios da nossa época, transformando nosso pensamento crítico em ação na e para a vida. 
Cristiana Caldas Guimarães de Campos Rua Nascimento Silva, 4, bloco C/ apto $804-$ Ipanema - Rio de Janeiro - RJ CEP: 22421-020

E-mail:criscaldas@ax.apc.org Tel: 021-3202-1629

Solange Jobim e Souza

Pontifícia Universidade Católica do Rio de Janeiro Departamento de Psicologia Rua Marquês de São Vicente, 225 -Gávea CEP: 22543-900 Rio de Janeiro E-mail:soljobim@psi.puc-rio.br Tel: $021-31141185$

Recebido 06/10/00 Aprovado 23/11/02

Bakhtin, M. (1997) Marxismo e filosofia da linguagem. São Paulo: Hucitec.

(1992) Estética da criação verbal. Martins Fontes, São Paulo.

Baudrillard, J. (1995) A sociedade de consumo. Elfos, Rio de Janeiro.

Benjamin, W. (1984) Reflexões sobre infância, educação e brinquedo Summus, São Paulo

(1987) Experiência e Pobreza. IN: Benjamin, W.

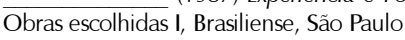

Canclini, N. (1997) Consumidores e Cidadãos - conflitos multiculturais da globalização UFRJ, Rio de Janeiro

Costa, J. F. (1995) A ética e o espelho da cultura. Rocco, Rio de Janeiro.

(1994) Vida: um princípio básico no bem-comum e na ética do convívio. Revista Proposta. N. 60. P. 10-15.

Featherstone, (1995) O desmanche da cultura. Nobel, São Paulo Paulo

(1995) Cultura do consumo e Pós-Modernismo. Nobel, São

Jobim E Souza, S. (1994) Infância e Linguagem. Papirus, Campinas.

(1996) Re-significando a psicologia do desenvolvimento In: Kramer, S. \& Leite, M. (org.) Infância: fios e desafios da pesquisa Papirus, Campinas
(1994) Infância e Linguagem - Bakhtin, Vygotsky e Benjamin, $\overline{\overline{\text { Papirus, }}}$ São Paulo

\& Kramer, S. (1991) O debate Piaget e Vygotsky e as políticas educacionais - Cadernos de Pesquisa da Fundação Getúlio Vargas n. 77, maio. São Paulo.

\& Rabello de Castro - (1997/8) Pesquisando com crianças: subjetividade infantil, dialogismo e gênero discursivo revista Psicologia Clínica - Pós-graduação \& pesquisa Volume 9 - Departamento de Psicologia - PUC - Rio

Kramer, S. \& Jobim e Souza, S. (1996) História de Professores Leitura, Escrita e Pesquisa, Ática, São Paulo

, Oliveira, M. e Dantas, H. (1992) Piaget, Vygotsky e Wallon - teorias psicogenéticas em discussão Summus, São Paulo

Lipovetsky, G. (1983) A era do vazio. Antropos, Relógio D’Água Editores Ltda, Lisboa

Pessanha, J. A. (1992) As delícias do jardim In: Novaes, A. (org.) Ética. Companhia das Letras, São Paulo

Postman, N. (1999) O desaparecimento da infância. Graphia, Rio de Janeiro

Rabello, L. (1995) Mudanças sociais e reordenamentos institucionais no limiar do século XXI: reflexões sobre a infância na sociedade de consumo Trabalho apresentado no Seminário Brasileiro de Psicologia. Psicologia em contexto, PUC-Rio

(org.) (1998) Infância e adolescência na cultura de consumo Nau, Rio de Janeiro
Referências bibliográficas

Sarlo, B. (1997) Cenas da Vida Pós-moderna. UFRJ, Rio de Janeiro 